contacted. The follow-up rate was $91 \%$, including 351 males and 75 females; including $333 \mathrm{PCI}$ therapies and $93 \mathrm{CABG}$ therapies. The average time of follow-up was $60.59 \pm 6.15$ months and the mean time of 60 months. Aging of the patients were from 31 to 84 years and average age of $59.68 \pm 10.82$ years; Incidence of MACCE was 84 patients $(19.7 \%)$, including re-MI 33 patients (7.7\%), TVR/TLR 48 patients $(11.3 \%)$, all-caused death 20 patients (4.7\%); Re-angina pectoris 139 patients (32.6\%), not-TVR/TLR 23 patients (5.4\%). Cox regression model analysis showed: OMI $(\beta=3.98, p=0.004$, $\mathrm{OR}=53.47,95 \%$ IC 3.59-795.74) stroke $(\beta=5.43, \mathrm{p}=0.001$, $\mathrm{OR}=228.31,95 \%$ IC 8.21-635.36) rhythmia $(\beta=6.37, p=0.008$, $\mathrm{OR}=586.44,95 \%$ IC 5.44-6319.54) smoking $(\beta=1.6, p=0.016$, $\mathrm{OR}=4.95,95 \%$ IC 1.34-18.31) hypertension $(\beta=2.78, p=0.002$, $\mathrm{OR}=16.18,95 \%$ IC $2.75-95.04)$ and the amount of lesion vessel $(\beta=3.029, p=0.002, O R=20.67,95 \%$ IC 3.056-139.829) were main risk factors of MACCE incidence; The past PCI $(\beta=-7.053, p=0.000, O R=0.001,95 \%$ IC: $0-0.032)$, hyperlipoidemia $(\beta=-1.74, p=0.034, \mathrm{OR}=0.18,95 \%$ IC: $0.035-0.877)$ might have had protective effect on the cohort. Survival curve decreased more sharply in 1 year and 4-5 years than other time during following-up.

Conclusion OMI, stroke, arhythmia, smoking, hypertension and the amount of lesion vessel were independent prediction factors. The time of 1 year and 4-5 years after revascularisation might be two "time windows" of higher MACCE incidence.

\section{[gw22-e0559] THE LONG-TERM (>5 YEARS) FOLLOWING-UP STUDY AND ANALYSIS OF INFLUENCING FACTORS IN CORONARY HEART DISEASE PATIENTS AFTER REVASCULARISATION}

Hongbin Liu, Guowei Wang The Chinese Pla General Hospital, Beijing, China

10.1136/heartjnl-2011-300867.464

Objective To follow-up and study the long-term incidence of the major adverse cardiac and cerebrovascular events (MACCE) and the influence factors of coronary heart disease patients in our centre.

Methods Four hundred and sixty eight patients who underwent revascularisation (percutaneous coronary intervention or coronary artery bypass graft) from January 2004 to March 2006 were selected in the study. All patient were followed-up by telephone, rehospitalisation and mail, this is a single-centre and non-control study. Observing patients' clinical characteristics, examination results, operation information and SYNTAX score had influence on incidence of MACCE. The major end point was MACCE (including all-caused death re-myocardial infarction, target vessel revascularisation/target lesion revascularisation); the secondary end point were Re-angina pectoris and non-target vessel revascularisation.

Results Four hundred and twenty six patietns finished successfully over 6 years following-up. Forty two patients failed to be 